\title{
Polymers and Scaffolds with Improved Blood Compatibility and Enhanced Cellular Response with Focus on Polyurethane Foams Functionalized with Amino-Amide Groups
}

\author{
Maria Cristina Tanzi $i^{1, *}$, Daniel Gantz ${ }^{2}$, Serena Bertoldi ${ }^{1,2}$, Nicola Contessi Negrini ${ }^{1,2}$ and \\ Håvard Jostein Haugen ${ }^{3}$
}

${ }^{1}$ INSTM local unit, Politecnico di Milano, Dept of Chemistry, Materials and Chemical Engineering "G. Natta", Milano, Italy

${ }^{2}$ Dept of Chemistry, Materials and Chemical Engineering "G. Natta", Politecnico di Milano, Milano, Italy

${ }^{3}$ Dept. of Biomaterials, Inst. of Clinical Dentistry, University of Oslo, Geitmyrsveien 71, 0455 Oslo, Norway

\begin{abstract}
Biofunctionalization of biomaterial substrates has gained increasing interest in Tissue Engineering (TE) to create functional scaffolds with improved performances and capable of directing cellular behaviour. This work takes into account the functionalization of polyurethane (PU) foams with an active molecule, the diamino-diamide diol PIME, purposely designed to be inserted in the structure of linear PUs and previously found to be able to improve hemo-, cytocompatibility and bacterial resistance of these biomaterials. Here, for the first time, the gas foaming process previously set up for biocompatible PU foams was modified, and different methods were tested to obtain structurally stable foams containing PIME. The obtained foams and respective controls showed appropriate porosity $(\varnothing=407 \div 589$ $\pm 30 \mathrm{um} ;>90 \%$ open porosity), similar density $\left(\approx 0.14 \mathrm{~g} / \mathrm{cm}^{3}\right)$ and hydrophilicity (water uptake $\left.\approx 300 \%\right)$ and adequate compressive properties $\left(E=0.058 \div 0.170 \mathrm{Mpa}\right.$; Hysteresis Area $=2.07 \div 5.59 \times 10^{-3} \mathrm{~J}_{\mathrm{cm}}{ }^{3},<5 \%$ residual deformation) PU foams containing PIME exhibited a more spherical pore geometry; the foam obtained by applying a higher stirring speed during synthesis (PU-3kP) exhibited a lower mean pore size and an elastic modulus higher than that of the other foams. FT-IR spectroscopy indicated the presence of new absorption bands and structural changes attributable to the presence of PIME. Cytotoxicity tests performed with the cell line L929 verified the absence of cytotoxic effects. All foams were able to support L929 fibroblasts proliferation and vitality for seven days; PIME-containing foams showed higher values of cell proliferation $(p<0.05)$ that the respective controls.
\end{abstract}

Keywords: Polyurethane foams, scaffold, functionalization, bioactive molecule, PIME, open porosity, compressive properties, cell interactions, L929, fibroblasts.

\section{INTRODUCTION}

Tissue Engineering (TE) strategies usually consists of the design of a biomaterial scaffold or substrate able to support seeded cells and maintain them growing and proliferating at the site or tissue of action [1]. These biomaterial substrates, therefore, influence the attachment, proliferation and functionality of regenerative cells [2] and should behave as bioinstructive scaffolds capable of directing cellular behavior.

A further request for a functional scaffold is the ability to promote adequate vascularization to support growth, function, and viability of tissue substitutes that require blood vessel supply. This aspect is presently a prevalent challenge in TE [3].

Interactions with cells are directed by chemical composition, surface energy, mechanical properties (e.g., stiffness), topography and roughness of the scaffold surface at the interface with the host

*Address correspondence to this author at the Piazza L. da Vinci 32, 20133 Milano, Italy; Tel: 0039022399 3362; E-mail: mariacristina.tanzi@polimi.it

E-ISSN: 2311-1755/19 microenvironment. A suitable biomaterial substrate should display adequate pore size, open porosity, mechanical strength, degradation properties, and biocompatibility. In addition, when in contact with blood, it should present adequate thrombus resistance [4].

Over the years, studies on biofunctionalization of biomaterial substrates (i.e., modification with biologically active molecules) have gained importance [5]. Among the considered strategies to overcome thrombogenesis, one of the best approaches has been the immobilization of heparin onto the synthetic surface [4]. Heparin is a highly negatively charged glycosaminoglycan (GAG) containing sulphonic and carboxylic groups and also one of the most commonly used natural anticoagulant drugs for treatment and prevention of blood clotting and thrombus formation [6]. Besides this, heparin exerts a variety of biological activities [7].

Among several approaches for heparin immobilization [4], the development of polymeric structures able to interact and strongly retain heparin appeared very promising. In particular, linear polymers carrying tertiary amino groups in alternation with amido 
groups (TAG-AG), named poly-amido-amines (PAAs), demonstrated the ability to form stables complexes with heparin, via strong ionic and electrostatic interactions owing to their protonation behaviour at physiological $\mathrm{pH}$ [8].

PAAs were therefore of interest in biomedical applications for the preparation of heparin absorbing resins and heparinizable antithrombogenic materials; they were also surface-grafted to enhance the hemocompatibility of the material $[9,10]$.

Following the promising experiences with PAAs, the introduction of TAG-AG short sequences in the polymer backbone was subsequently considered. For this purpose, the Authors designed a tailor-made diol bearing the functional groups of interest, i.e. the diamino-diamide-diol PIME $[11,12]$. The structure of PIME is shown in Scheme 1.

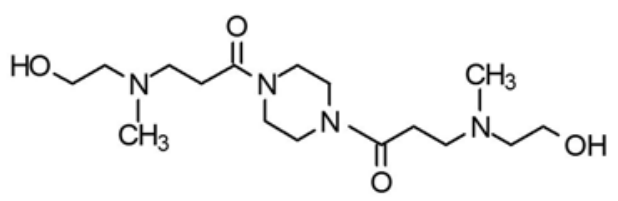

Scheme 1: Chemical formula of the diamino-diamide-diol PIME (1,4-bis $\{\beta-[N-m e t h y l-N-(2-h y d r o x y e t h y l)$ amino] propionyl\} piperazine). The $\mathrm{OH}$ end groups allow for the insertion in the backbone of polymers (e.g. polyurethanes) during polymerisation, whereas the presence of tertiary amino groups (which are positively charged at physiological $\mathrm{pH}$ ) alternating with amido groups allow for interaction with heparin.

PIME showed a very good cytocompatibility, therefore well fitting with the synthesis of biomedical polymers. In particular, Human Umbilical Cord Endothelial Cells (HUVEC) grown in the presence of PIME gave vitality values identical or even slightly higher than the control, indicating a good ability of this new compound to promote cell growth [11, 12].

Many polymeric structures, in principle, can be obtained with PIME, ranging from linear to crosslinked, with hydrophilic/hydrophobic, biostable/bioabsorbable properties.

An initial approach was that to design and prepare linear polyurethanes and hydrogels, and a series of PIME-containing materials was prepared and fully characterized [13-15]

It is important to emphasize that, even not heparinized, PIME-containing polyurethanes (PUPIMEs) showed the capability of promoting cell adhesion and growth [13].
The heparin binding ability of PU-PIMEs was evaluated with ${ }^{125} \mathrm{I}$ labelled heparin. The obtained results indicated a significantly higher heparin binding ability of PIME-containing PUs and more stable than that of other polyurethanes, with a time dependent kinetics [14]. The interaction with heparin appears to be prevalently ionic, with the contribution of other electrostatic and hydrophobic interactions; coagulation tests performed with human plasma using PU-PIME coated and heparinized test tubes indicated that heparin maintains its biological activity after adsorption and after sterilization $[13,16]$.

Polymers incorporating the PIME group can bind heparin by a simple immersion in a dilute heparin solution at physiological $\mathrm{pH}$. This is a much simpler approach than currently used methods for surface heparinization, which require multi-step treatments to enable binding to standard biomaterials [4].

Furthermore, PIME was proven to be able to provide heparin-retaining ability to a commercial biomedical polyurethane (i.e., the polycarbonateurethane Bionate ${ }^{\mathrm{TM}}$ ) even when inserted in low bulk amounts $(0.1-0.5 \% \mathrm{w} / \mathrm{w}$, besides a traditional chain extender) [17].

The ability to prevent bacterial adhesion was also investigated on the same Bionate-PIME polyurethanes and compared with two commercial medical-grade polymers used for fabrication of long-term catheters in blood-contacting applications. Beside the local control of the coagulation process, the adsorption of heparin onto Bionate-PIME surface was shown to play a role in mediating bacterial cells interaction. Heparinized Bionate-PIME surfaces were able to decrease the colonization ability of the bacterial strains mainly involved in the pathogenesis related to medical device infections (S. Epidermidis and S. Aureus) [18].

In the present work, for the first time, the Authors investigated the possibility of inserting PIME in the structure of polyurethane foams during synthesis.

Polyurethane porous structures are being studied extensively for 3D scaffolds applications in Tissue Engineering [19-21] since this versatile family of copolymers displays excellent mechanical properties, mechanical flexibility, good processability and biocompatibility.

In the recent years, the Authors' research group acquired the know-how for the preparation of biocompatible polyurethane foams prepared by a one- 
Table 1: Composition of the PU Foams. PIME-Containing Foams: PUf-2kP, PUf-3kP, PUf-TP80. PUf and PUf-T80 are the Corresponding Control Foams, not Containing PIME

\begin{tabular}{|c|c|c|c|c|c|}
\hline & Component name & PUf & PUf-2kP, PUf-3kP & PUf-T80 & PUf-TP80 \\
\hline & (OH number) & \multicolumn{4}{|c|}{ (weight \%) } \\
\hline \multirow{6}{*}{ 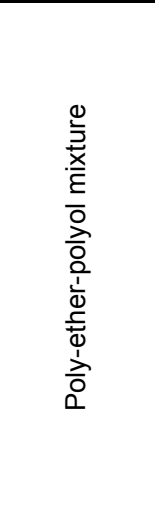 } & $\begin{array}{l}\text { (*) Desmophen 10WF18 }^{*}(28.6 \mathrm{mgKOH} / \mathrm{g})\end{array}$ & 85.73 & 85.30 & 85.73 & 85.30 \\
\hline & $\begin{array}{l}{ }^{(*)} \text { Desmophen 7619W } \\
(128.8 \mathrm{mgKOH} / \mathrm{g})\end{array}$ & 10.05 & 10.00 & 10.05 & 10.00 \\
\hline & $\begin{array}{l}{ }^{(*)} \text { Desmophen 4051B } \\
(467.4 \mathrm{mgKOH} / \mathrm{g})\end{array}$ & 2.01 & 2.00 & 2.01 & 2.00 \\
\hline & $\begin{array}{c}{ }^{(*)} \text { Butanediol } \\
(1245 \mathrm{mgKOH} / \mathrm{g})\end{array}$ & 1.01 & 1.00 & 1.01 & 1.00 \\
\hline & $\begin{array}{l}{ }^{(*)} \text { Ethylene Glycol } \\
(1810 \mathrm{mgKOH} / \mathrm{g})\end{array}$ & 1.01 & 1.00 & 1.01 & 1.00 \\
\hline & PIME & & 0.5 & - & 0.5 \\
\hline \multirow{3}{*}{ 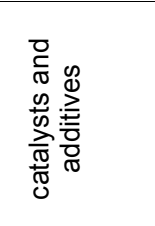 } & $\begin{array}{c}{ }^{(* *)} \text { DABCO 33-LV } \\
(1,4-\text { diazabicyclo[2.2.2] octane) }\end{array}$ & 0.10 & 0.10 & 0.10 & 0.10 \\
\hline & ${ }^{(* *)}$ K Acetate & 0.10 & 0.10 & 0.10 & 0.10 \\
\hline & $\begin{array}{c}{ }^{(* *)} \text { Fe-Acetylacetonate (FeAA) } \\
\geq 99.9 \%\end{array}$ & 0.001 & 0.001 & - & - \\
\hline $\begin{array}{l}\text { Poly iso- } \\
\text { cyanate }\end{array}$ & \multicolumn{5}{|c|}{ Modified MDI (4-4'-methylene diphenyl diisocyanate), Desmodur@ PF (*) } \\
\hline $\begin{array}{l}\text { Expanding } \\
\text { agent }\end{array}$ & \multicolumn{5}{|c|}{ distilled water $=2 \% \mathrm{w} / \mathrm{w}_{\text {polyol }}$} \\
\hline
\end{tabular}

$\left({ }^{\star}\right)=$ Covestro AG; $\left({ }^{*}\right)=$ Sigma-Aldrich .

step expansion procedure using water as expanding agent [22-24]. Among other applications, the developed 3D PU scaffolds were investigated for bone tissue engineering [25] and as in vitro model for breast cancer bone metastasis [26]. However, by an appropriate selection of the regents and relative stoichiometry, PU scaffold could be designed for regeneration of soft tissues, such as skin and adipose tissue.

The purpose of this paper is to describe the work done with the intention of inserting PIME in the PU foam formulation, to improve cell-scaffold interactions, hemocompatibility and, possibly bacterial resistance and scaffold vascularization.

\section{MATERIALS AND METHODS}

\section{Synthesis of the Diamino-Diamide-Diol PIME ${ }^{1}$}

PIME was synthesized from bis-acryloyl-piperazine - BAP- and N-methyl-ethanol-amine - MEA - (both purchased from Sigma-Aldrich), using a molar ratio of

\footnotetext{
${ }^{1}$ The name PIME derives from the union of Piperazine with $\underline{\text { MEA }}$
}

1:2 respectively, and then fully characterized as described in refs. [11, 12].

The reaction consists in the addition of $\mathrm{NH}$-methyl groups of MEA to the acrylic double bonds of BAP following a Michael-type mechanism and is performed in methanol, at room temperature for $48 \mathrm{~h}$. Isolation and purification of the final product are performed by precipitating and whashing twice the white powder product in diethylether at room temperature. PIME is crystalline, with a molecular weight $=344.45 \mathrm{~g} / \mathrm{mol}$ and melting point $=110-111^{\circ} \mathrm{C}(\Delta \mathrm{H}$ melting $=197,9 \mathrm{~J} / \mathrm{g})$.

\section{Synthesis of Polyurethane Foams}

PU foams were obtained by a previously optimized one-step gas foaming reaction [25], by reacting an ad hoc prepared poly-ether-polyol mixture and additives with a polyisocyanate (a modified diphenyl-methane4,4'-diisocyanate, MDI), using water as expanding agent and Fe-Acetylacetonate (FeAA, Iron(III) acetylacetonate $\geq 99.9 \%$, Sigma-Aldrich) as reaction catalyst. The composition of the control foams and PIME-containing ones is shown in Table 1.

The one-step process involves, in sequence: 
I. Preparation of the polyol mixture with reaction additives ( $\mathrm{K}$ acetate and DABCO, Table 1 ) and titration of its water content with an automated Karl Fischer (METTLER $®$ DL); addition of the appropriate quantity of Fe-AcetylAcetonate (FeAA, $0.001 \% \mathrm{w} / \mathrm{w})$ and distilled water $(2 \% \mathrm{w} / \mathrm{w}$, taking into account the quantity already present, as indicated by titration);

II. Mechanical stirring (ALCW750, MAVER) in a PP beaker at $2000 \mathrm{rpm}$ for 40 seconds;

III. Addition of the appropriate amount of MDI (modified 4-4'-methylene diphenyl diisocyanate, $\mathrm{NCO}=5.476 \mathrm{mmol} / \mathrm{g}$, Desmodur PF, Covestro AG, Germany), so to obtain a non-stoichiometric ratio of $\mathrm{OH}: \mathrm{NCO}$ groups $=100: 133$, with an isocyanate excess;

IV. Mechanical stirring at $2000 \mathrm{rpm}$ for 30 seconds or until the mixture overheats, which indicates the beginning of the polymerization.

Then, the reaction mixture is quickly poured inside a custom-made poly(methyl methacrylate) mold ( $\mathrm{V}=500$ $\mathrm{cm}^{3}$ ), the mold is firmly closed using stainless steel screws and kept at room temperature (R.T.) for $72 \mathrm{~h}$ to allow for the complete expansion process. At complete reaction, the foam is manually removed and the compacted surface skins (thickness $\cong 0.5 \mathrm{~cm}$ ) are gently cut and discarded, so to obtain a homogeneous porous structure (control foam, named PUf). The foam is finally post-cured at R.T. for 3 days before subsequent characterization.

\section{PIME-Containing Foams}

In the case of PU foams containing PIME it was necessary to modify the process in such a way to include this new compound without modifying stoichiometry and altering homogeneity of the reacting mixture.

In particular, PIME is insoluble in the mixture of polyols and suitable solvents (e.g., water, methanol, chloroform) can create technical difficulties.

Before carrying out the synthesis, PIME powder was dried in oven at $40^{\circ} \mathrm{C}$ for $24 \mathrm{~h}$.

Among different tested procedures, two in particular were able to produce structurally stable PU foams:

1) Addition of PIME powder $(0.5 \% \mathrm{w} / \mathrm{w})$ to the reaction mixture after titration of the polyol mixture but before adding MDI. Two mechanical stirring conditions for $1 \mathrm{~min}$ were tested, the first at 2000rpm after adding PIME and the second at $3000 \mathrm{rpm}$, with the aim to obtain the most homogeneous mixing possible. Foams prepared with this process were named PUf-2kP and PUf$3 \mathrm{kP}$ (where $\mathrm{P}$ means PIME and $2 \mathrm{k}$ or $3 \mathrm{k}$ indicate mechanical stirring respectively of 2000 or 3000rpm);

2) The process is analogous to the previous one and consists in adding PIME powder $(0.5 \% \mathrm{w} / \mathrm{w})$ to the reaction mixture as in 1), but the synthesis was carried out at $80^{\circ} \mathrm{C}$, by putting the filled mold in oven for $72 \mathrm{~h}$, with the aim of improving the kinetics of the foaming reaction. In this case, the addition of the catalyst FeAA was not necessary. The foam obtained with this process was named PUf-TP80 (where P means PIME and 80 indicates the temperature in ${ }^{\circ} \mathrm{C}$ ); for comparison, a foam was prepared in the same way, but without PIME (PUf-T80).

\section{PU Foams Physical Characterization}

Density was evaluated according to EN ISO 845 standard practice [27], by measuring the volume and weighing PU foam cylindrical samples $(n=5 ; \varnothing=15$ $\mathrm{mm}, \mathrm{h}=10 \mathrm{~mm}$, cut from each foam with a mechanical die) in dry conditions, after conditioning for $24 \mathrm{~h}$ at 25 ${ }^{\circ} \mathrm{C}$.

Morphology of the PU foams was investigated by Scanning Electron Microscopy (SEM, Stereoscan 360, Cambridge Instrument). All the specimens were sputter-coated with gold (Edwards Sputter Coater $5150 \AA)$ and observed in secondary electron detection mode at $10 \mathrm{keV}$.

Porosity, average pores size and pores size distribution were evaluated by micro CT analysis at the Institute of Clinical Dentistry of the University of Oslo (Norway). Cylindrical samples $(\varnothing=6 \mathrm{~mm}, \mathrm{~h}=4 \mathrm{~mm}, \mathrm{n}$ $=5$ ) for each type of foam were examined. The analyses were carried out with the $1172 \mu$-CT imaging system (Bruker microCT $\AA$, Aartselaar, Belgium) at 2.9 $\mu \mathrm{m}$ voxel resolution, $155 \mu \mathrm{A} X$-ray tube current, and 40 $\mathrm{kV}$ voltage without filters. Specimens were rotated through $180^{\circ}$ around the long axis of the sample, with a rotation of $0.4^{\circ}$. Projection radiographs of the sample were reconstructed to serial coronal-oriented tomograms using a 3D cone beam reconstruction algorithm, setting the beam hardening to $20 \%$ and the 
ring artifact reduction to 12 . $3 \mathrm{D}$ reconstruction of the internal pore morphology was carried out using axial bitmap images and analyzed by CTan and CTvol softwares (Bruker microCT®, Aartselaar, Belgium). The grey scale threshold was set between 45 and 255 , removing all objects smaller than 400 voxels and not connected to the 3D model. To eliminate potential edge effects, the cylindrical volume of interest (VOI) was selected in the center of a scaffold $(\varnothing=2.5 \mathrm{~mm}, \mathrm{~h}=2$ $\mathrm{mm})$. Scaffold porosity was then calculated from equation (1):

porosity $=100 \%-$ vol $\%$ of binarised object (scaffold materials) in $\mathrm{VOI}$

The mean pore diameter distribution was determined by measuring the material thickness on the inverse model generated by setting grey scale threshold between 0 and 45. The 3D models were generated through the algorithm adaptive rendering.

To evaluate the PU foams chemical structure,_FT-IR analysis was performed in transmission mode on $2 \mathrm{D}$ samples obtained by withdrawing a known mass of the reaction mixture before transferring it to the mold and spreading it on a glass plate using a plastic spatula equipped with a foamed PVC profile (FLEX GEKO®).

Spectra were acquired with the spectrophotometer Spotlight 400 FT-IR Imaging System (Perkin Elmer®) with a resolution of $16 \mathrm{~cm}^{-1}$ in the range of $4000-700$ $\mathrm{cm}^{-1}$.

Water uptake tests were performed on PU foam cylindrical samples $(\varnothing=15 \mathrm{~mm}, \quad \mathrm{~h}=10 \mathrm{~mm})$. Dried samples were immersed in distilled water at $37^{\circ} \mathrm{C}$. At different time points (until reaching the plateau value of absorption) samples were extracted from the water, wiped with filter paper to remove liquid in excess, and weighed. The percentage water uptake (WU\%) was calculated according to the formula (2):

Water Uptake $(\%)=\frac{w_{i}-w_{0}}{w_{0}} \times 100$

where $w_{0}$ is the dry weight and $w_{i}$ is the wet weight at the time point $\mathrm{i}$.

To evaluate the mechanical properties, compression tests were carried out on cylindrical specimens $(\varnothing=15 \mathrm{~mm}, \mathrm{~h}=10 \mathrm{~mm}, \mathrm{n}=3)$. Uniaxial mechanical tests were performed with a MTS Bionix testing machine (MTS System, Minneapolis, MN, USA), at a crosshead rate of $1 \mathrm{~mm} / \mathrm{min}$, with a $0.5 \mathrm{~N}$ preload, in wet condition, i.e. by maintaining the specimens in distilled water at $37^{\circ} \mathrm{C}$ for all the test time in a homemade thermostatic chamber, until reaching $95 \%$ of samples deformation. Cyclic compression tests were also performed, by applying the load until the attainment of a $50 \%$ deformation of the specimens height and subsequently removing it for 5 times.

The most significant derived parameters were:

- Elastic modulus (E, MPa), expressed as the slope of the straight line interpolating the first linear section of the stress/strain curve;

- $\quad$ Area of the hysteresis cycle $\left(A_{\text {hyst }}\right)$, or hysteresis area (index of energy dispersion), calculated with the Origin $®$ program.

\section{Cytotoxicity Tests}

The possible release of cytotoxic or unreacted substances from the PU foam was investigated by indirect cytotoxicity tests according to ISO 10993 standard using L929 murine fibroblasts cell line (ECACC No. 85011425).

All PU foam samples $(\varnothing=10 \mathrm{~mm}, \mathrm{~h}=3 \mathrm{~mm})$ were immersed in pure ethanol (Sigma-Aldrich) for $48 \mathrm{~h}$, to allow the disinfection and the complete removal of possible low molecular weight by products and then let dry at room temperature. PU samples were then disinfected in $70 \% \mathrm{v} / \mathrm{v}$ ethanol solution in water for 30 min and then sterilized by exposition to UV light (10 $\min$ for each side, $\lambda=254 \mathrm{~nm}$ ).

To obtain the eluates, PU samples ( $n=3$, per time point) were put in a 48-multiwell tissue culture plate (TCPS), immersed in $700 \mu \mathrm{L}$ of complete Dulbecco's Modified Eagle Medium (DMEM, Sigma Aldrich) and incubated for 1,3 and 7 days.

L929 cells (density $=1 \times 10^{4}$ cells $/$ well) were seeded in the 96-multiwell TCPS and cultured for $24 \mathrm{~h}$ to allow cell adhesion on the well bottom. After that, the medium was replaced with the obtained DMEM eluates, using DMEM only as control. After $24 \mathrm{~h}$ of culture, cell viability was investigated with the Alamar Blue colorimetric assay (Invitrogen Life Technologies, Monza, Italy) [28] following manufacturer's instructions. Briefly, culture medium was replaced with fresh culture medium containing alamarBlue solution and incubated at $37{ }^{\circ} \mathrm{C}$ for $4 \mathrm{~h}$. Then, $100 \mu \mathrm{L}$ of supernatants were transferred from each well to a new 96-multiwell TCPS plate and fluorescence $\left(\lambda_{\text {excitation }}=540 \mathrm{~nm}, \lambda_{\text {emission }}=\right.$ 
$595 \mathrm{~nm}$ ) was read by a spectrophotometer (Tecan, Genius Plus plate reader). Cell viability was calculated by relating the fluorescence detected for cells cultured in the presence of eluates of PU foam samples to the fluorescence related to cells cultured with controls (DMEM medium only) and subtracting the background fluorescence of Alamar Blue solution.

Cytocompatibility tests (i.e. by direct contact) were performed to investigate the ability of $\mathrm{PU}$ foams to support L929 cells proliferation. PU foam samples $(n=$ $4 ; \varnothing=10 \mathrm{~mm}, \mathrm{~h}=4 \mathrm{~mm}$ ) were sterilized as above described and preconditioned for $30 \mathrm{~min}$ in complete DMEM. L929 cells were drop-seeded (density $=2 \times 10^{4}$ cells/sample) on the PU foam samples and on TCPS, as control. Cells viability was evaluated by Alamar Blue assay after 1,3 , and 7 days of culture.

\section{Statistical Analysis}

Data normal distribution was checked before each statistical analysis. Data are reported as mean and standard deviation. Statistical analysis (Origin 7.0 software) was performed using ANOVA tests, with significance level $p=0.05$.

\section{RESULTS AND DISCUSSION}

The synthetic processes described were successful to obtain structurally stable and highly porous foams functionalized with PIME.

Density and water uptake values are reported in Table 2, together with data of control foams not containing PIME. All the foams showed density values comparable with no significant differences ( $p>0.05)$, proving that both the presence of PIME and the different synthesis conditions did not affect the apparent density of the foams.

Water uptake at equilibrium reached similar values, corresponding to an increase of weight near $300 \%$.
Despite the higher hydrophilicity of PIME, its presence in a very low percentage did not have a significant influence (i.e. not significant differences due to the high values of standard deviation) on the water uptake of the PU foams although the tendency of the foams containing this compound is to retain more water.

Morphology of the synthesized foams was qualitatively evaluated by SEM observation and quantitatively with $\mu$-CT analyses.

SEM images evidenced that, in general, all PU foams are characterized by a macro-porous structure with interconnections between pores, thus identifying a high open porosity and well interconnected porous structure (Figure 1 a1-d1). PU foams containing PIME (Figure $1 \mathrm{~b} 1, \mathrm{c} 1$ and $\mathbf{e 1}$ ) present a more spherical pore geometry compared to the other foams that exhibit more elongated pores with greater dimensions (Figure 1 a1, d1).

These observations were confirmed with the $\mu$-CT analysis, demonstrating that all the foams display an open porosity higher than $90 \%$ and corresponding to the percentage of detected total porosity (Table 2). Mean diameters of the pores are shown in Table 2; it can be noticed that PUf-3kP and PUf-2kP present a lower mean pore diameter $(p<0.05)$ compared to the control foams not containing PIME. PUf-TP80, while containing PIME, presents a mean pore diameter comparable to its control foam; this possibly indicates that both the presence of PIME and the higher temperature of synthesis influenced the morphology of the foams, the pores actually have a spherical geometry, but their dimensions are comparable with those of foamed materials not containing PIME.

Models of PU foam samples reconstructed using $\mu$ CT are represented in Figure 1 a2-e2.

Compression mechanical tests confirmed that both PIME and temperature influenced the properties of the

Table 2: Physical Properties of PU Foams

\begin{tabular}{|c|c|c|c|c|c|c|c|}
\hline PU foam & $\begin{array}{l}\text { Density } \\
\left(\mathbf{g} / \mathrm{cm}^{3}\right)\end{array}$ & $\begin{array}{l}\% \text { Water } \\
\text { uptake (^) }\end{array}$ & $\begin{array}{c}\text { Mean pore } \varnothing, \\
\mu \mathrm{m}(\S)\end{array}$ & $\begin{array}{c}\% \text { Total } \\
\text { porosity (§) }\end{array}$ & $\begin{array}{c}\% \text { Open } \\
\text { porosity (§) }\end{array}$ & $\mathrm{E}(\mathrm{MPa})\left(^{*}\right)$ & $\begin{array}{c}\text { Hyst. Area } \\
\left(\mathrm{J} / \mathrm{cm}^{3}\right) \times 10^{-3}\left({ }^{\circ}\right)\end{array}$ \\
\hline PUf & $0.134 \pm 0.006$ & $234.59 \pm 5.24$ & $589.00 \pm 41.71$ & $91.96 \pm 0.14$ & $91.96 \pm 0.14$ & $0.067 \pm 0.004$ & $2.07 \pm 0.04$ \\
\hline PUf-2kP & $0.137 \pm 0.002$ & $298.97 \pm 48.60$ & $452.83 \pm 45.07$ & $91.32 \pm 0.78$ & $91.32 \pm 0.78$ & $0.140 \pm 0.020$ & $3.64 \pm 0.16$ \\
\hline PUf-3kP & $0.141 \pm 0.001$ & $337.03 \pm 59.20$ & $407.47 \pm 35.18$ & $90.46 \pm 0.35$ & $90.46 \pm 0.35$ & $0.170 \pm 0.010$ & $5.59 \pm 0.45$ \\
\hline
\end{tabular}

$\left({ }^{\wedge}\right)$ at the plateau value of absorption $(240 \mathrm{~h}) ;(\S)$ values obtained from micro-CT analyses; $\left({ }^{*}\right)$ as obtained in uniaxial compression tests until $95 \%$ deformation; $\left({ }^{\circ}\right)$ derived from $1^{\text {st }}$ compression cycle. 

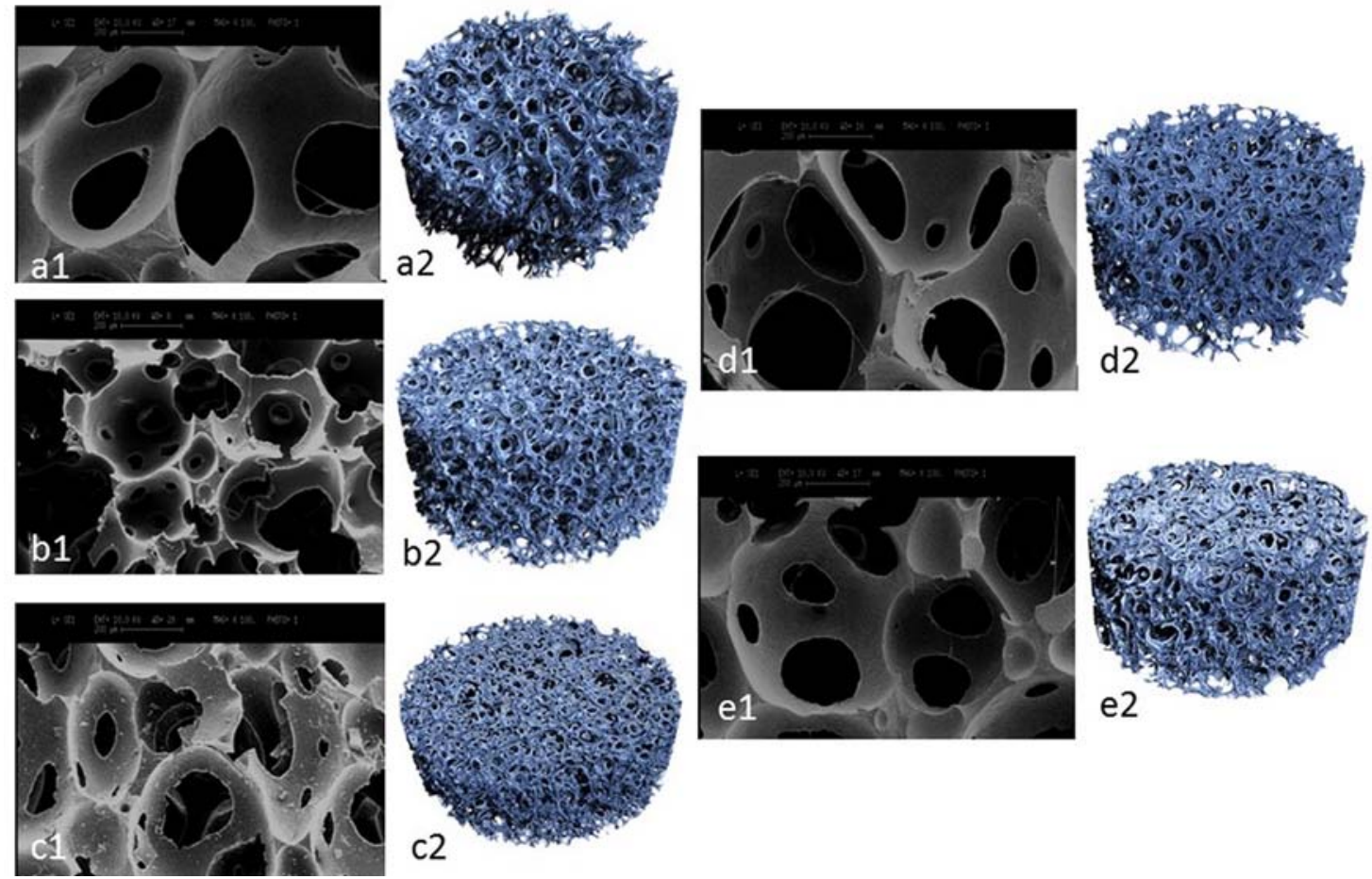

e2

Figure 1: SEM representative images of $P U$ foams (cross-section, 100x): a1) control PUf, b1) PU-2kP, c1) PU-3kP, d1) control PU-T80, e1) PU-TP80; $\mu \mathrm{CT}$ recontructed models of PU foam samples: a2) control PUf, b2) PU-2kP, c2) PU-3kP, d2) control PU-T80, e2) PU-TP80.

PU foams. The elastic modulus values obtained from uniaxial compression tests performed until reaching $95 \%$ of deformation are shown in Table 2. It can be noticed that PUf-3kP specimens exhibited an elastic modulus higher than that of the other foams, proving a direct role of PIME towards the mechanical behaviour, probably related to the lower pore size of the foam. However, the $E$ value displayed by PUf-2kP resulted lower than that of $3 \mathrm{kP}$, even containing PIME. A possible explanation could be that the mechanical mixing at 2000rpm during the foam synthesis is not sufficient to make homogeneous the reaction mixture and therefore PIME distribution inside the foam structure.

The results of cyclic compression tests of the five PU foams samples are shown in Figure 2.

Figure 2A shows the curves that relate the elastic modulus to the number of cycles for all the foams analyzed. A greater stiffness is confirmed for PUf-3kP foam, displaying an elastic modulus always greater than that of the other foams, with higher values after the first cycle; for this foam, E decreases with the second cycle and subsequently remain substantially constant as the number of cycles increases. The decrement of E, visible in a lower extent also for PU$2 \mathrm{kP}$ from the first and second cycle, can be attributed to the breaking of the walls of some pores after the first loading cycle, generating an even more interconnected structure. The only significant differences $(p<0.05)$ in the elastic modulus of PUf-2kP foam are between the first and the fifth cycle. From the second to the fifth cycle the elastic modulus of PUf-3kP is not statistically different $(p>0.05)$ from that of PUf-2kP, whereas both foams present, at all considered cycles, a modulus significantly higher $(p<0.05)$ than the ones of control PUs (PUf, PUf-T80) and PUf-TP80, for which the trend of the elastic modulus does not show significant differences $(p>0.05)$ between the various cycles.

The trend of the hysteresis area_values from the first to the fifth cycle for all the PU foam types is reported in Figure 2B, whereas $\sigma / \varepsilon$ curves of the five cycles are shown in Figure 2C for PUf-T80 and PUf-TP80 and in Figure 2D for PUf-2kP PUf-3kP and control PUf.

The curves that represent the hysteresis area as a function of the number of cycles for all foams show significantly higher stress values for type $2 \mathrm{kP}, 3 \mathrm{kP}$ and respective control. For all foams the hysteresis area shows statistically significant differences $(p<0.05)$ between the first cycle and the subsequent 4 cycles, which do not show significant differences among them ( $p>0.05$ ). Values of the hysteresis area for first cycle are reported in Table 2. 


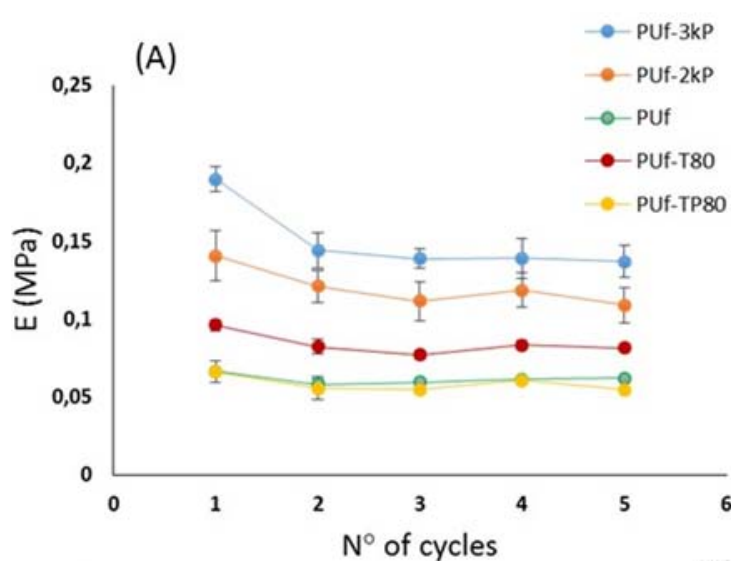

(C)

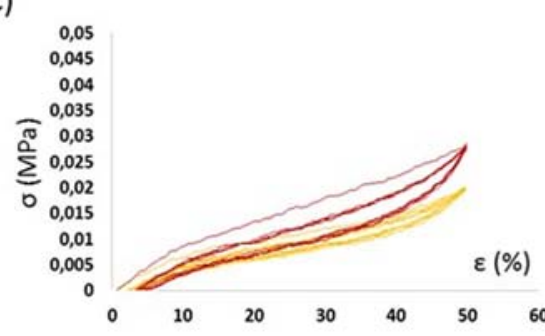

(B)

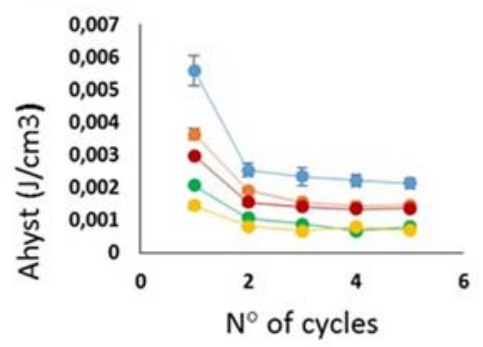

(D)

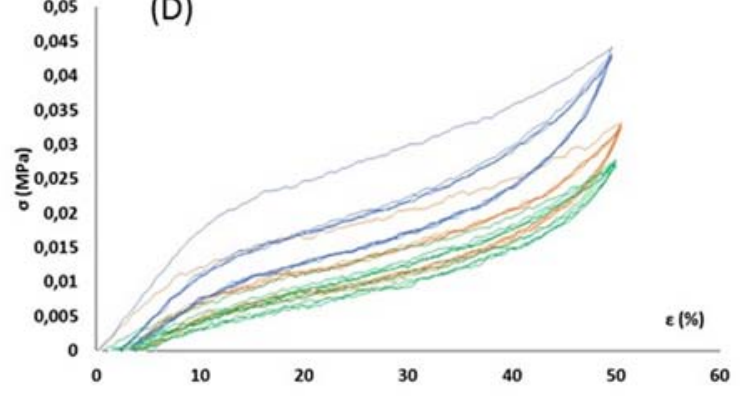

Figure 2: Trend of the considered mechanical parameters during cycle 1-5 in cyclic compression tests for the five PU foam types. (A): Elastic modulus (E), (B): Hysteresis Area $\left(A_{\text {hyst }}\right),(C)$ : graphical representation of the hysteresis area for PU foams PU-T80 (red lines) and PU-TP80 (yellow lines), (D): graphical representation of the hysteresis area for PU foams PUf (green line), PU-2kP (blu line) and PU-3kP (orange lines)

In all cases, it can be noticed that residual deformation values, after unloading, are small and in the range of $2 \%$ and $5.3 \%$, denoting an elastomeric behaviour for all considered PU foams.

\section{FT-IR Analysis}

FTIR spectra of 2D PU samples were recorded in transmission, in the range of $4000-700 \mathrm{~cm}^{-1}$. From the IR pattern (dotted line) of Figure $\mathbf{3 A}$ and $\mathbf{B}$, the typical absorption bands of polyurethane foam are detectable: the stretching of $\mathrm{N}-\mathrm{H}$ bond in the range of $3500-3300$ $\mathrm{cm}^{-1}$ with a vibration in-plane peak at $3274 \mathrm{~cm}^{-1}$; the stretching of $\mathrm{O}-\mathrm{H}$ bond at 2925 and $2863 \mathrm{~cm}^{-1}$. Typical peaks of the urethane group are detectable at 1708 $\mathrm{cm}^{-1}$ ( $\mathrm{C}=\mathrm{O}$ stretching), at $1625 \mathrm{~cm}^{-1}$ (amide I) and 1546 $\mathrm{cm}^{-1}$ (amide II). Other characteristic peaks are the stretching vibrations of C-N (amide III, $1224 \mathrm{~cm}^{-1}$ ), of CO $\left(1016 \mathrm{~cm}^{-1}\right)$, and of C-C $\left(902 \mathrm{~cm}^{-1}\right)$; the rocking vibration of $\mathrm{C}-\mathrm{H}\left(811 \mathrm{~cm}^{-1}\right)$; the wedging vibration of $\mathrm{N}$ $\mathrm{H}$ bond in secondary amines $\left(763 \mathrm{~cm}^{-1}\right)$.

Figure $\mathbf{3 A}$ and $\mathbf{B}$ (solid line) shows a spectrum of a 2D PU sample containing PIME, where it is possible to see some absorption bands that are not present in the spectrum of the sample without PIME. These bands, between 1370 and $1310 \mathrm{~cm}^{-1}$, are attributable to the aliphatic tertiary amine stretching of PIME and the one in the range of $1300-1150 \mathrm{~cm}^{-1}$ is attributable to the stretching of PIME tertiary amide $(\mathrm{C}-\mathrm{N})$. Marked differences can be observed in the region between 1700 and $1400 \mathrm{~cm}^{-1}$. These differences are attributable to changes in the structural arrangement of the polymer chains caused by the presence of PIME.

\section{In Vitro Cytotoxicity Tests}

In vitro cytotoxicity tests were performed on the $\mathrm{PU}$ foam with the murine fibroblasts cell line L929 to verify the absence of a possible release of cytotoxic compounds. Considering the superior behaviour of PUf-3kP compared to PUf-2kP, the latter was excluded from in vitro tests with cells.

The viability (i.e., the metabolic activity measured with Alamar Blue test) of the cells in culture with the eluates obtained after 1, 3 and 7 days of contact with the foam samples is shown in Figure 4.

Values reported in Figure 4 demonstrate that cell viability was near $100 \%$ (or even higher) for every considered time point of extraction, with no significant differences among them, thus indicating that no cytotoxic products were released from the PU foams. 


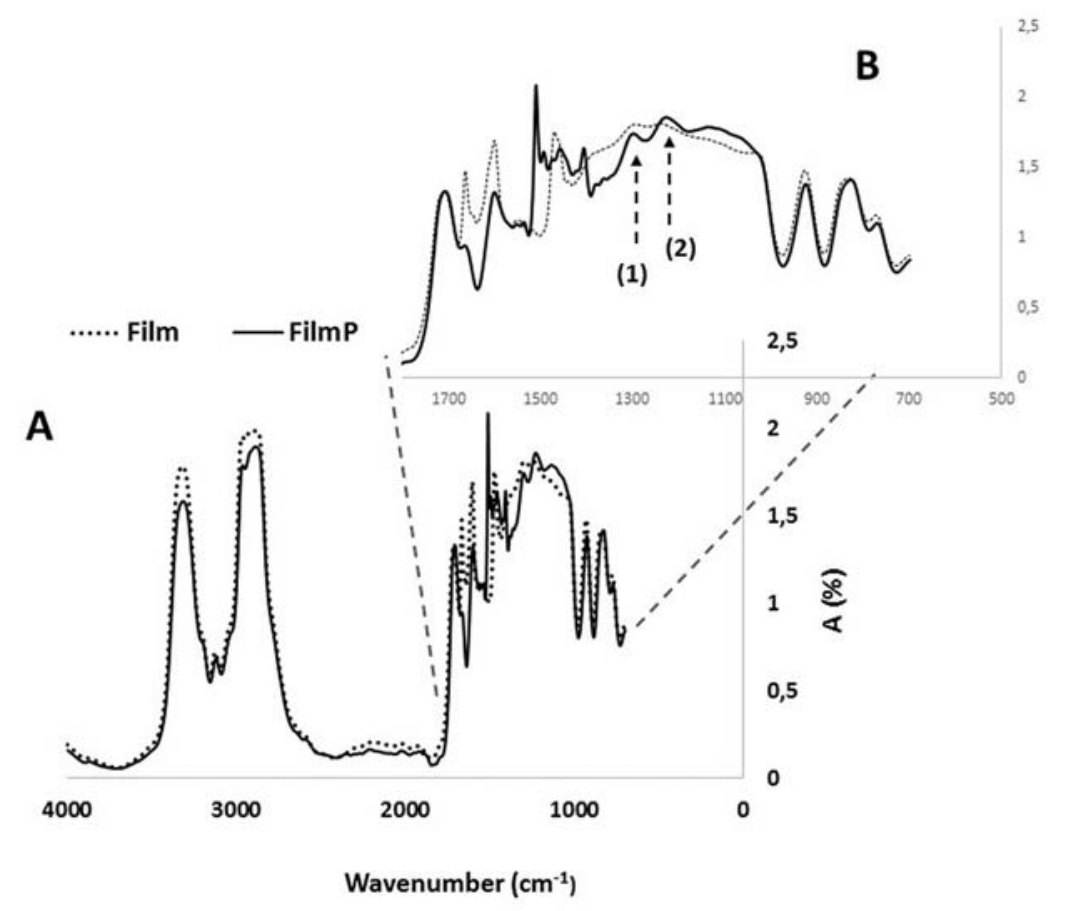

Figure 3: Representative FT-IR spectra of 2D samples: control PU (Film, dotted line) and PIME containing PU (FilmP, solid line). A: IR spectra in the range of $4000-700 \mathrm{~cm}^{-1}$; B: magnification of the spectral region between 1800 and $700 \mathrm{~cm}^{-1}$. The arrows indicate the absorption bands of inserted PIME: (1) stretching of aliphatic tertiary amine, (2) stretching of tertiary amide bond.

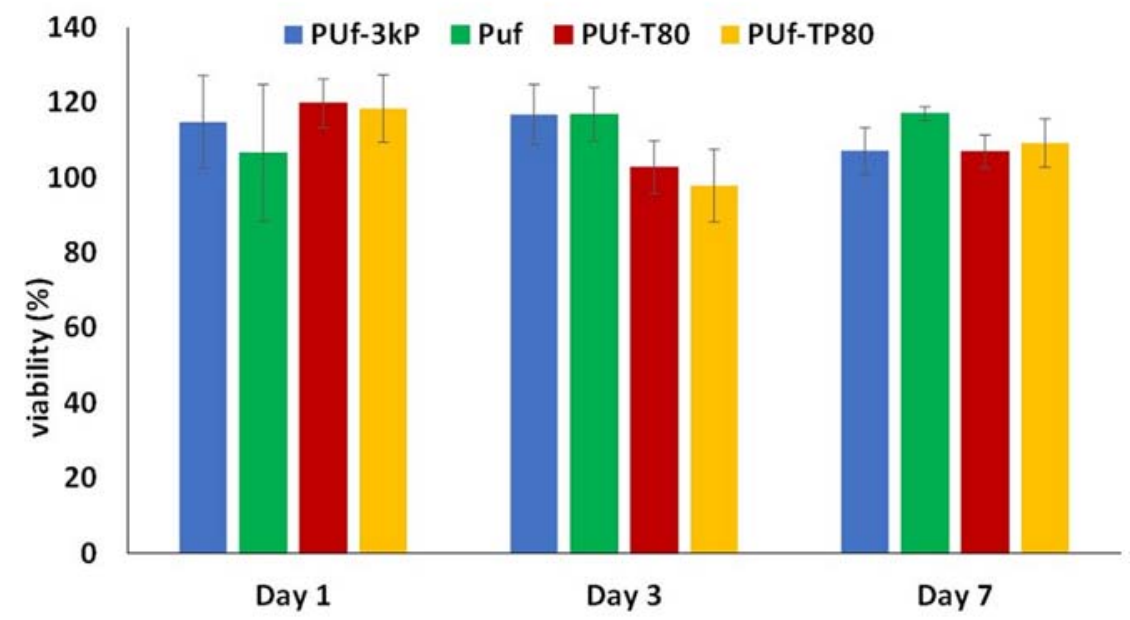

Figure 4: Cell viability of L929 cells cultured for $24 \mathrm{~h}$ in the presence of eluates obtained after immersion of PU foam samples for 1,3 and 7 days in DMEM culture medium.

\section{In Vitro Cytocompatibility Tests}

Preliminary tests of direct cytocompatibility were performed on the four selected PU foams to assess their ability to support L929 cell adhesion and proliferation after 1,3 , and 7 days of culture after seeding.

The data obtained from the analysis in fluorescence (Alamar Blue assay) were processed by subtracting the
Relative Fluorescence Units (RFU) values of the cellseeded samples from the RFU values of the nonseeded samples, so as to evaluate only the emission caused by the presence of cells.

The results obtained are shown in Figure $\mathbf{5}$. It is possible to assert that all foam samples are able to support cell proliferation and vitality for seven days, as the number of viable cells (i.e., increase of RFU values) increase over time. 


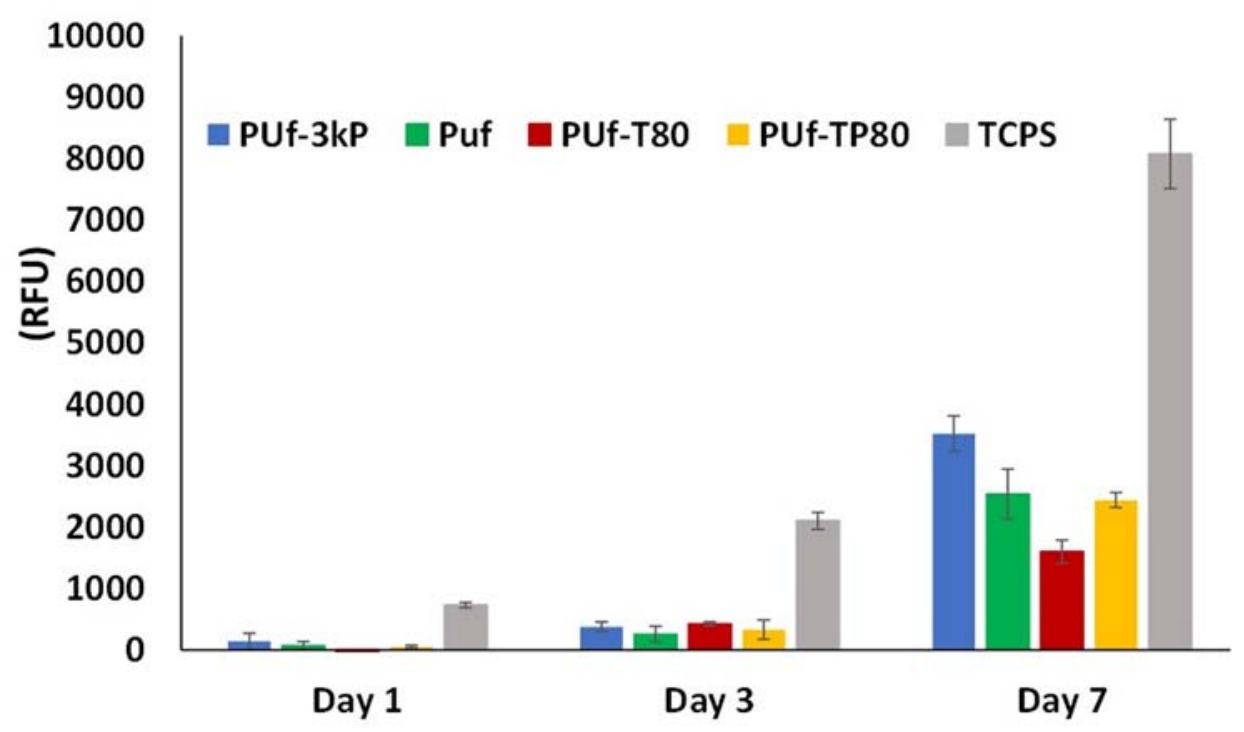

Figure 5: Values of Relative Fluorescence Units (RFU) for L929 cells cultured onto PU foam samples at 1.3 and 7 days.

At each time point RFU values of cells seeded on the TCPS wells is significantly greater $(p>0.05)$ than that of cells cultured onto the foam samples. This can be explained by the different morphology of PU foam samples (porous, 3D) compared to TCPS (2D, and specifically treated to promote cell adhesion and proliferation). On the other hand, at day 7 , both PIMEcontaining $\mathrm{PU}$ foams support higher values of cell proliferation $(p<0.05)$ compared to their respective control foams.

It can therefore be asserted that the morphology of the foams is not the only aspect that influences the adhesion and growth of cells, but also that the presence of PIME can increase the cytocompatibility of the PU foams, as already hypothesized for linear thermoplastic polyurethanes containing PIME [4].

\section{CONCLUSIONS}

In this research work different types of PU foams containing PIME were synthetized and characterized, demonstrating for the first time in literature the possibility of inserting PIME in a porous PU structure without collapsing.

According to the previous results with Bionate ${ }^{\mathrm{TM}}$ [17], the Authors decided to start using a small percentage of PIME $(0.5 \mathrm{w} / \mathrm{w}$ of the polyol mixture) since the expansion process is highly sensitive even to small variation in the reacting mixture composition that could induce instability (i.e., a collapse) of the foam.

Interestingly, the addition of the small amount of PIME influenced the kinetic of expansion, accelerating it [29], possibly due to the presence of tertiary amino groups in its structure.

All the tested procedures allowed for the production of foams with properties suitable for a possible use as scaffolds in Tissue Engineering.

All the prepared PU foams showed an open porosity $>90 \%$ and a macro-porous structure, with pores of dimensions suitable to promote cell adhesion and proliferation. The presence of PIME moieties in the chemical structure of the foams was confirmed by FTIR analysis.

The diamino-diamide diol PIME, although added in low concentration $\left(0.5 \% \mathrm{w} / \mathrm{w}_{\text {polyolmixture }}\right)$, was able to modify morphological, mechanical and biological properties of the foams. PIME-containing PU foams demonstrated diverse mechanical (compressive) properties. In particular, PUf- 3kP and PUf-2kP exhibited an elastic modulus higher than that of the other foams.

In vitro cytotoxicity and cytocompatibility tests were performed with the murine fibroblasts cell line L929, often selected as a reference cell line for preliminary tests. The obtained results indicated the absence of cytotoxicity and the ability of the foams to support cell adhesion and proliferation up to seven days.

The results obtained in this work confirm the possibility of functionalizing PU foams with the diaminodiamide diol PIME and open new perspectives in the research aimed at improving the performance of $\mathrm{PU}$ foams used as scaffolds in TE. 
Even though the results for interaction with cells are promising, it would be useful to perform long-time cytocompatibility tests with different cell types, particularly with endothelial cell to explore potential angiogenetic stimuli of PIME-containing foams, with or without heparinization.

Future investigations will be therefore addressed to assess the influence of PIME molecule on the properties of foams, and in particular on the ability to promote cell colonization and bacterial resistance and, hopefully, stimulate scaffold's vascularization.

\section{ACKNOWLEDGEMENTS}

The Authors are grateful to Covestro Srl (Filago BG, Italia) for supplying the products for the synthesis of polyurethane foams

\section{REFERENCES}

[1] Tanzi MC, Farè S, Candiani G. Tissue Engineering. In: Foundations of Biomaterials Engineering, Chapter 8.1. London: Academic Press 2019; pp. 471-512. https://doi.org/10.1016/B978-0-08-101034-1.00008-6

[2] Place ES, Evans ND, Stevens MM. Complexity in biomaterials for tissue engineering. Nat Mater 2009; 8: 457470.

https://doi.org/10.1038/nmat2441

[3] Bramfeldt H, Sabra G, Centis V, Vermette P. Scaffold Vascularization: A Challenge for Three-Dimensional Tissue Engineering. Current Medicinal Chemistry 2010; 17(33): 3944-67.

https://doi.org/10.2174/092986710793205327

[4] Tanzi MC. Bioactive technologies for hemocompatibility. Expert Rev. Med. Devices 2005; 2(4): 473-492. https://doi.org/10.1586/17434440.2.4.473

[5] Stevens MM, George JH. Exploring and engineering the cell surface interface. Science 2005; 310: 1135-8. https://doi.org/10.1126/science.1106587

[6] Byun Y, Jacobs HA, Kim SW. Mechanism of thrombin inactivation by immobilized heparin. J Biomed Mater Res 1996; 30: 423-427. https://doi.org/10.1002/jbm.820300403

[7] Oduah El, Linhardt RJ, Sharfstein ST. Heparin: Past, Present, and Future. Pharmaceuticals 2016; 9(38): 12. https://doi.org/10.3390/ph9030038

[8] Ferruti P, Marchisio MA, Duncan R. Poly(amido-amine)s: Biomedical Applications. Macromolecular Rapid Communications 2002; 23(5-6): 332-355.

https://doi.org/10.1002/15213927(20020401)23:5/6<332::AID-MARC332>3.0.CO;2-

[9] Tanzi MC, Barzaghi B, Anouchinsky R, Bilenkis S, Penhasi A, Cohn D. Grafting reactions and heparin adsorption of poly (amidoamine)-grafted poly (urethane amide)s. Biomaterials 1992; 13(7): 425-31. https://doi.org/10.1016/0142-9612(92)90162-H

[10] Albanese A, Barbucci R, Belleville J, Bowry S, Eloy R, Lemke $\mathrm{HD}$, Sabatini L. In vitro biocompatibility evaluation of a heparinizable material (PUPA) based on polyurethane and poly (amido-amine) components. Biomaterials 1994; 15: 129136

https://doi.org/10.1016/0142-9612(94)90262-3
[11] Tanzi MC. US5,955,560 Patent 1999. https://doi.org/10.1001/archopht.117.7.955

[12] Tanzi MC. US6, 143,893 Patent 2000. https://doi.org/10.1046/j.1365-2133.2000.03855.x

[13] Tanzi MC, Perini $P$, Farè $S$. Advanced polyurethanes for blood-contacting applications containing PIME as "smart" heparin-adsorbing moieties. In: Thomas DW, Ed.Advanced Biomaterials for Medical Applications. Dordrecht: Kluwer Academic Publ 2004; pp. 51-66. https://doi.org/10.1007/978-1-4020-2908-0_5

[14] Petrini P, Tanzi MC, Visai L, Casolini F, Speziale P. Novel Polyurethane-aminoamides: an in vitro study of the interaction with heparin. J Biomaterial Science Polymer Edition 2000; 11: 353-365. https://doi.org/10.1163/156856200743751

[15] Petrini P, Farè S, Bozzini S, Tanzi MC. Innovative HeparinBinding Polyurethane Hydrogel: Synthesis and Properties. In: Proc. of the VII World Biomaterials Congress 2004; p. 619.

[16] Petrini P, Visai L, Speziale P, Tanzi MC. HEPITAN: HeparinAdsorbing Properties. In: Transaction 6th World Biomaterials Congress 2000; p. 433.

[17] Ward RS, McCrea KR, Tian Y, Tanzi MC. Use of SFG to Optimize a Polyurethane with Heparin Binding Sites Incorporated During Synthesis. In: Proceedings of the 7th World Biomaterials Congress 2004; p. 433.

[18] De Nardo L, Farè S, Di Matteo V, Cipolla E, Saino E, Visai L, Speziale P, Tanzi MC. New heparinizable modified poly(carbonate urethane) surfaces diminishing bacterial colonization. J Mater Sci: Mater Med 2007; 18: 2109-2115. https://doi.org/10.1007/s10856-007-3083-9

[19] Szycher M, Szycher's Handbook of polyurethanes, 2nd Edition, Boca Raton: CRC 2013. https://doi.org/10.1201/b12343

[20] Janik H, Marzec M. A review: Fabrication of porous polyurethane scaffolds. Materials Science and Engineering: C 2015; 48: 586-591. https://doi.org/10.1016/j.msec.2014.12.037

[21] Gama NV, Ferreira A, Barros-Timmons A. Polyurethane Foams: Past, Present, and Future. Materials 2018; 11(10): 1841. https://doi.org/10.3390/ma11101841

[22] Tanzi MC, Farè $S$, Petrini $P$, Tanini $A$, Piscitelli $E$, Zecchi Orlandini S, Brandi ML. Cytocompatibility of polyurethane foams as biointegrable matrices for the preparation of scaffolds for bone reconstruction. J Appl Biomater Biomech 2003; 1(1): 58-66. https://doi.org/10.1177/228080000300100107

[23] Zanetta M, Quirici N, Demarosi F, Tanzi MC, Rimondini L, Farè S. Ability of polyurethane foams to support cell proliferation and the differentiation of MSCs into osteoblasts. Acta Biomater 2009; 5: 1126-1136.

https://doi.org/10.1016/j.actbio.2008.12.003

[24] Bertoldi S, Farè S, Denegri M, Rossi D, Haugen HJ, Parolini $\mathrm{O}$, Tanzi MC. Ability of polyurethane foams to support placenta-derived cell adhesion and osteogenic differentiation: Preliminary results. J Mater Sci Mater Med 2010; 21: 10051011.

https://doi.org/10.1007/s10856-009-3953-4

[25] Meskinfam M, Bertoldi S, Albanese N, Cerri A, Tanzi MC Imani R, Baheiraei N, Farokhi M, Farè S. Polyurethane foam/nano hydroxyapatite composite as a suitable scaffold for bone tissue regeneration. Materials Science and Engineering C 2018; 82: 130-140. https://doi.org/10.1016/j.msec.2017.08.064

[26] Angeloni V, Contessi N, De Marco C, Bertoldi S, Tanzi MC Daidone MG, Farè S. Polyurethane foam scaffold as in vitro model for breast cancer bone metastasis. Acta Biomaterialia 2017; 63: 306-316

https://doi.org/10.1016/j.actbio.2017.09.017 
[27] UNI EN ISO 845: 2006, "Cellular plastics and rubbers Determination of apparent density.

[28] Nakayama GR, Caton MC, Nova MP, Parandoosh Z. Assessment of the Alamar Blue assay for cellular growth and viability in vitro. J Immunol Methods 1997; 204: 205-8. https://doi.org/10.1016/S0022-1759(97)00043-4
[29] Tanzi MC, Gantz D, Bertoldi S, Negrini NC, Haugen HJ. Functionalized polyurethane foams as tissue scaffolds with enhanced cellular response. In: Transactions of the Annual Meeting of the Society for Biomaterials 2009; p. 691.

Received on 29-11-2019

Accepted on 14-12-2019

Published on 24-12-2019

DOI: http://dx.doi.org/10.12970/2311-1755.2019.07.03

(C) 2019 Tanzi et al.; Licensee Synergy Publishers.

This is an open access article licensed under the terms of the Creative Commons Attribution Non-Commercial License (http://creativecommons.org/licenses/by-nc/3.0/) which permits unrestricted, non-commercial use, distribution and reproduction in any medium, provided the work is properly cited. 